\title{
The Modern Phillips Curve Revisited
}

\author{
Jinpeng Ma \\ Department of Economics, Rutgers University, Camden, USA \\ Email: Jinpeng@crab.rutgers.edu
}

Received 1 February 2014; revised 1 March 2014; accepted 8 March 2014

Copyright (C) 2014 by author and Scientific Research Publishing Inc.

This work is licensed under the Creative Commons Attribution International License (CC BY).

http://creativecommons.org/licenses/by/4.0/

c) (i) Open Access

\begin{abstract}
The modern Phillips curve is about the relationship between the average rates of inflation and unemployment. We will provide additional empirical evidence in the US economy from 1948:01 to 2013:03 that helps demonstrate why such a relationship has been built on a wrong methodology, as revealed in Ma [1]. An erroneous approach can lead to a misunderstanding of business cycles and a wrongful implementation of monetary policy. In particular, the way how the two rates may evolve is now at a critical moment for the Fed to decide if an exit from its quantitative easing should be initiated.
\end{abstract}

\section{Keywords}

Phillips Curve; Business Cycle; Inflation; Unemployment

\section{Introduction}

The modern Phillips curve is about the relationship between the average rate of inflation and the average rate of unemployment. The use of average rates was initiated by A. W. Phillips [2], a methodology that has been in large inherited by a large number of subsequent studies [3] [4]. Ma [1] provided empirical evidence that shows why such a relationship between the two average rates can mislead. Useful information about how the two rates may evolve during business cycles has been lost with this average approach. Such an erroneous approach can lead to a misunderstanding of business cycles and a wrongful implementation of monetary policy of the Federal Reserve.

In this paper, we provide additional evidence why a search for a relationship between the average rates is not fruitful (Figure 1). However, useful information can be seen by plotting the two rates along a full business cycle (Figures 2-12). A main conclusion of this paper is that inflation increase is to a large extent of a phenomenon of "excess demand" and inflation decrease is to a large extent of a phenomenon of "excess supply". That is, a key observation in Phillips [2] below has held well for price inflation in the US economy since 1948, with his "excess demand" condition fulfilled near the end of an expansion with a substantial duration: 


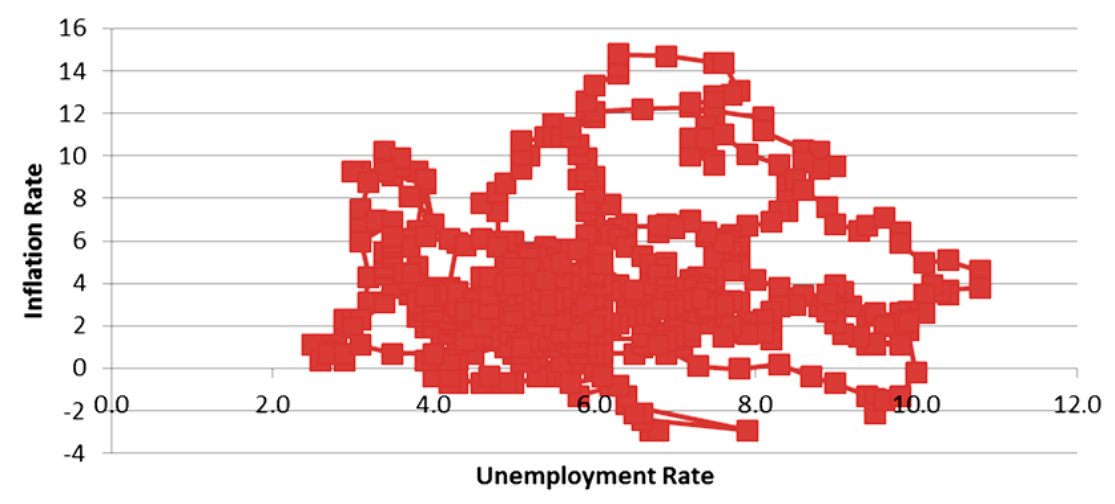

Figure 1. Chaotic pattern: monthly data 1948:01 - 2013:03.

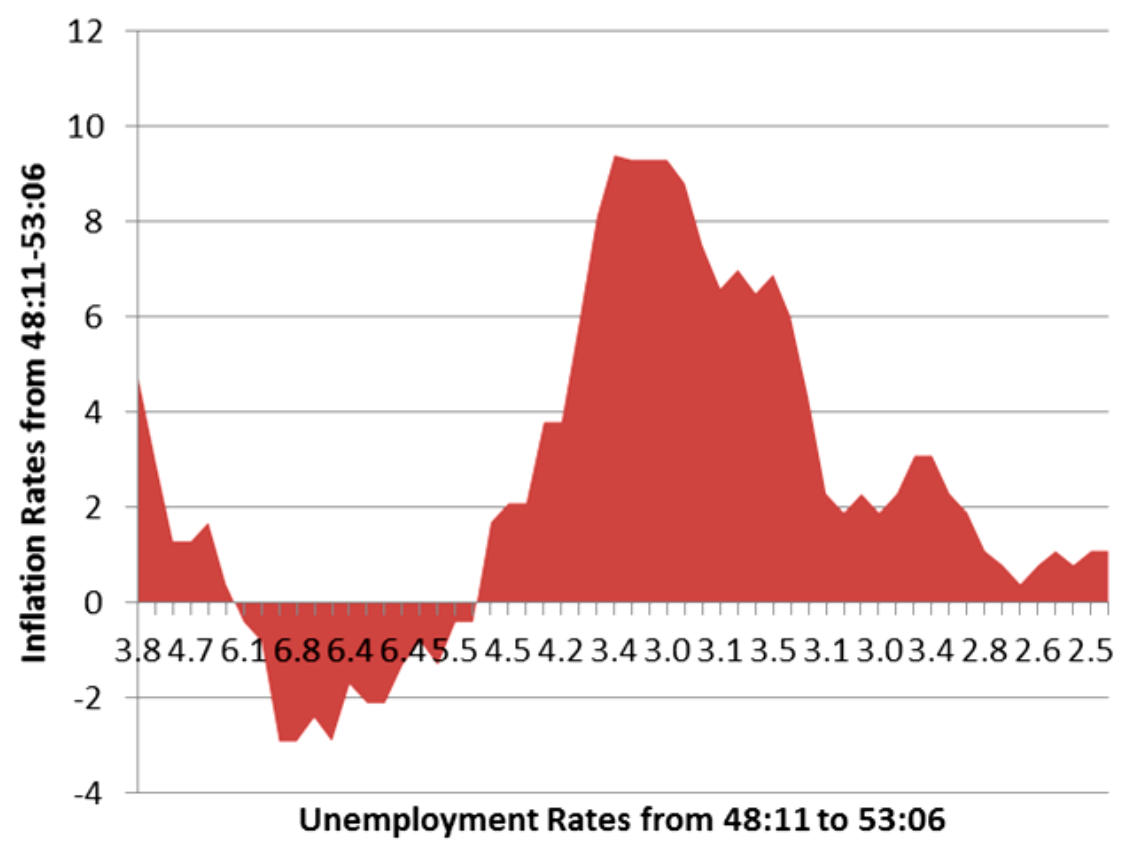

(a)

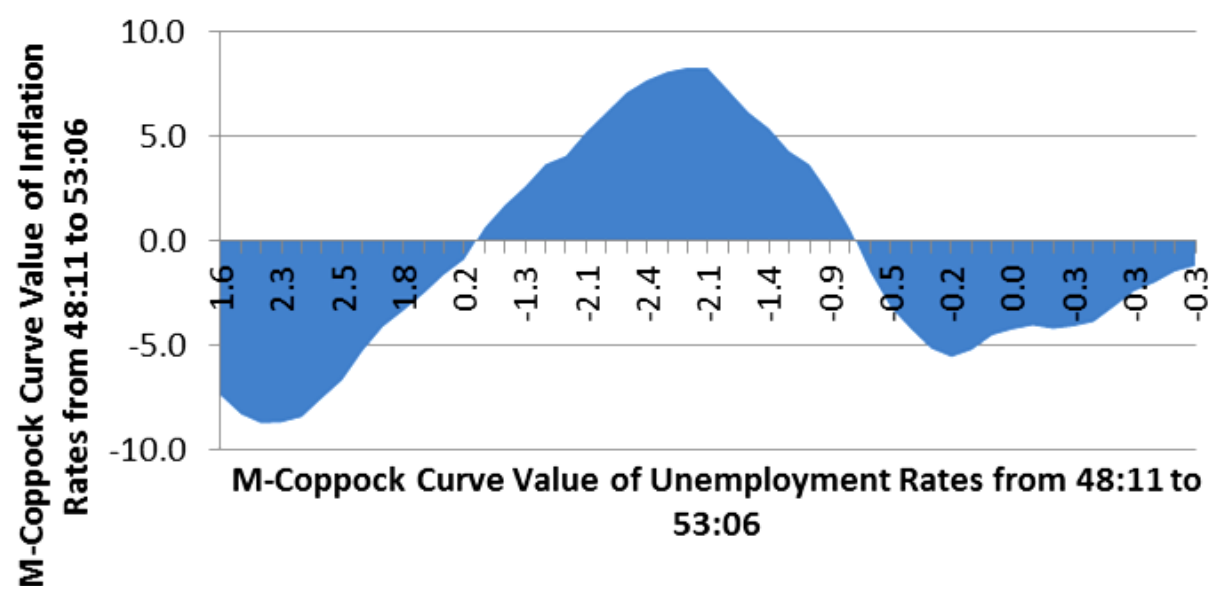

(b)

Figure 2. (a) Phillips curve, monthly from 48:11 - 53:06; (b) Phillips curve of M-Coppock curves: 48:11 - 53:06. 


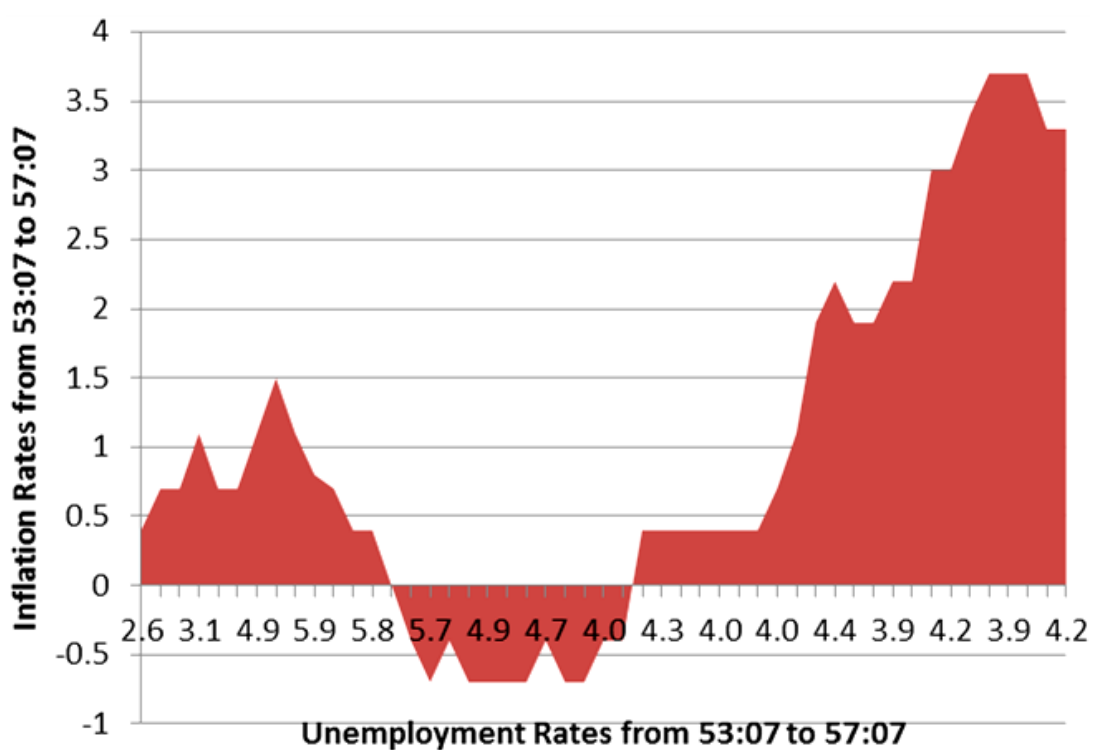

(a)

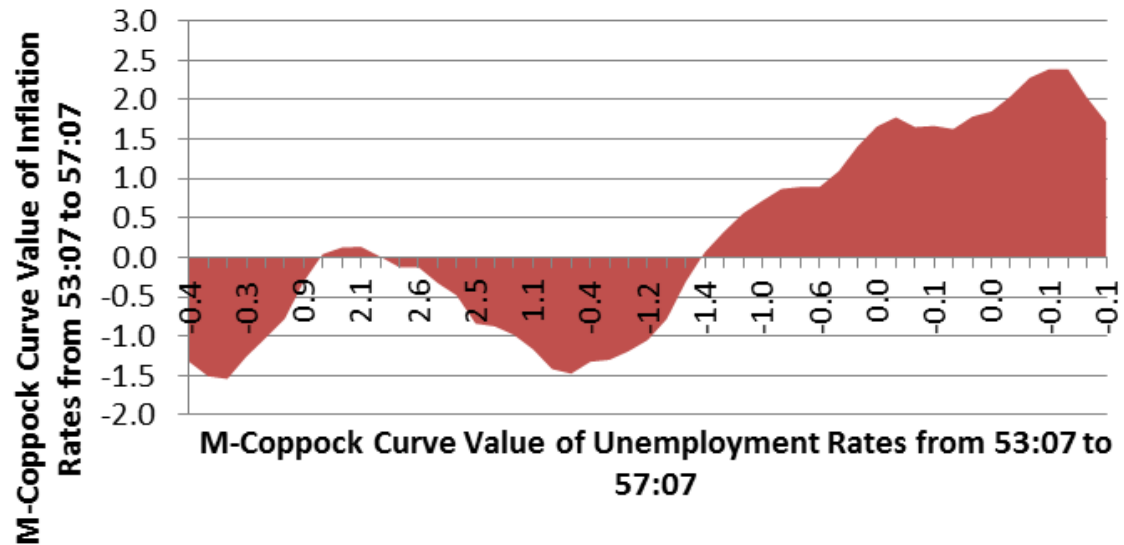

(b)

Figure 3. (a) Phillips curve, monthly from 53:07-57:07; (b) Phillips curve of M-Coppock curves: 53:07 - 57:07.

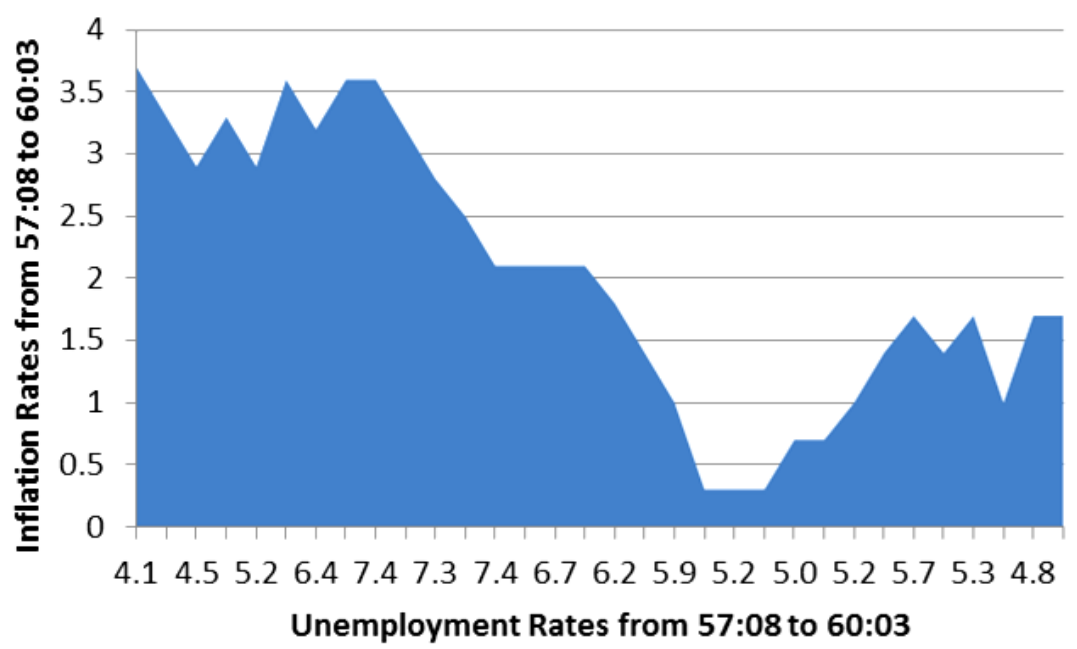

(a) 


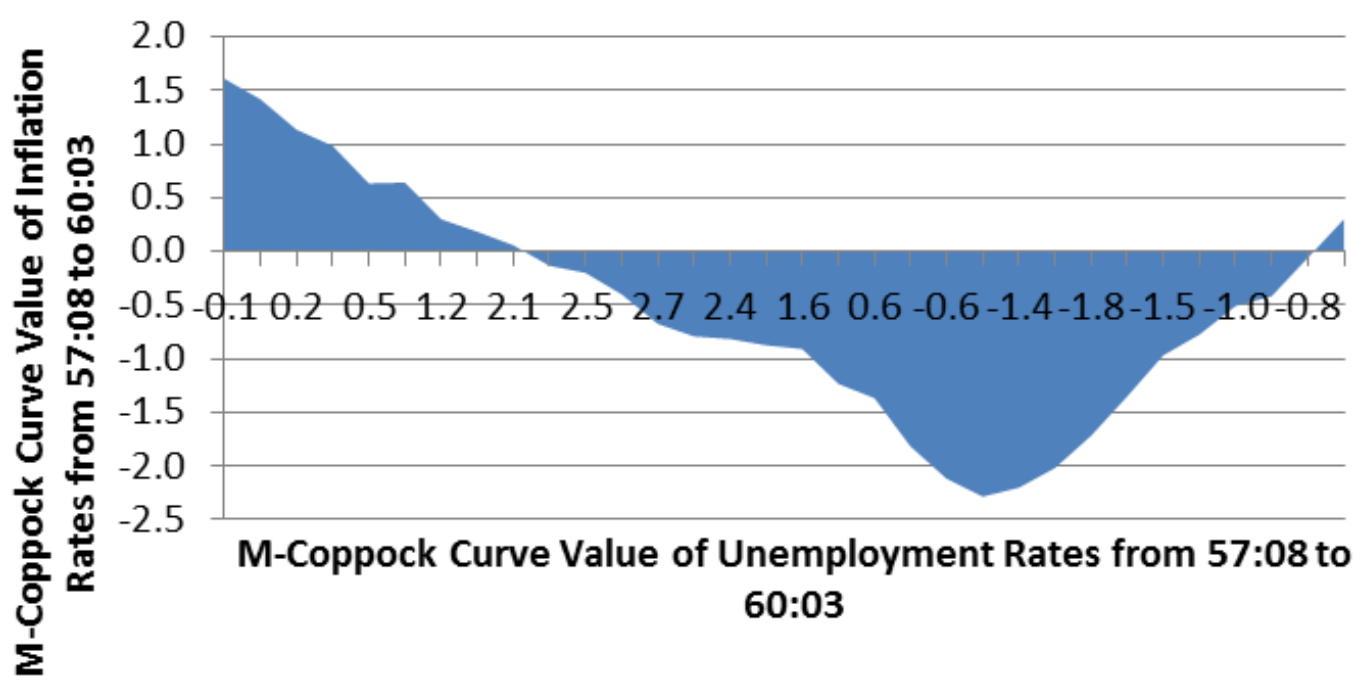

(b)

Figure 4. (a) Phillips curve, monthly from 57:08 - 60:03; (b) Phillips curve of M-Coppock curves: 57:08 60:03.

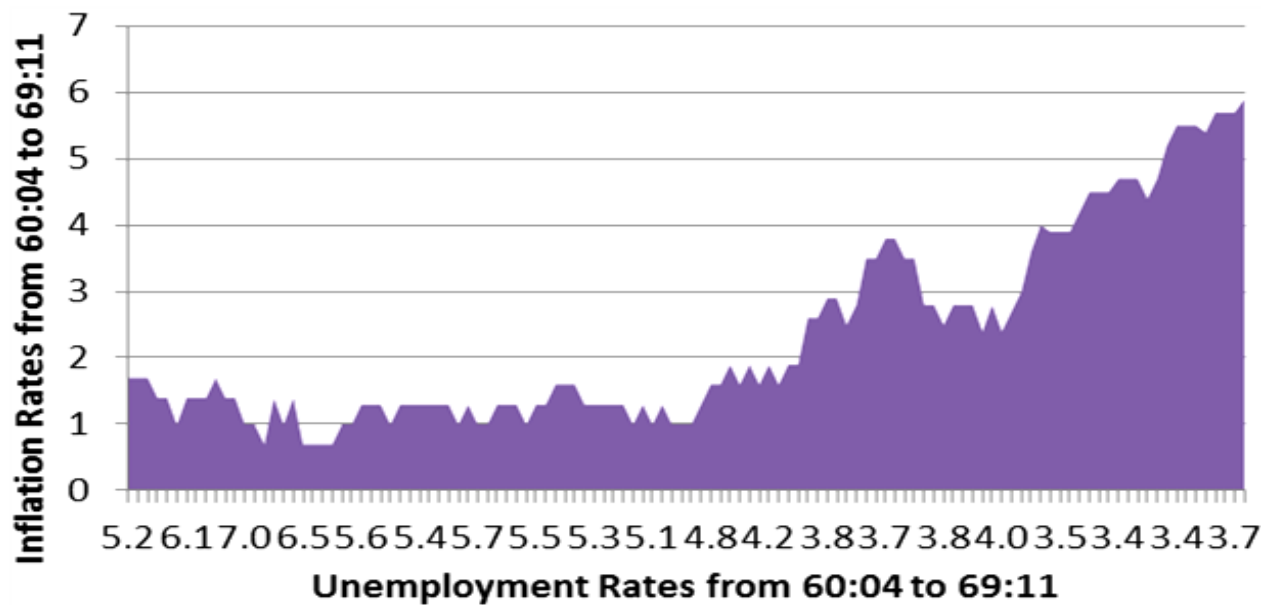

(a)

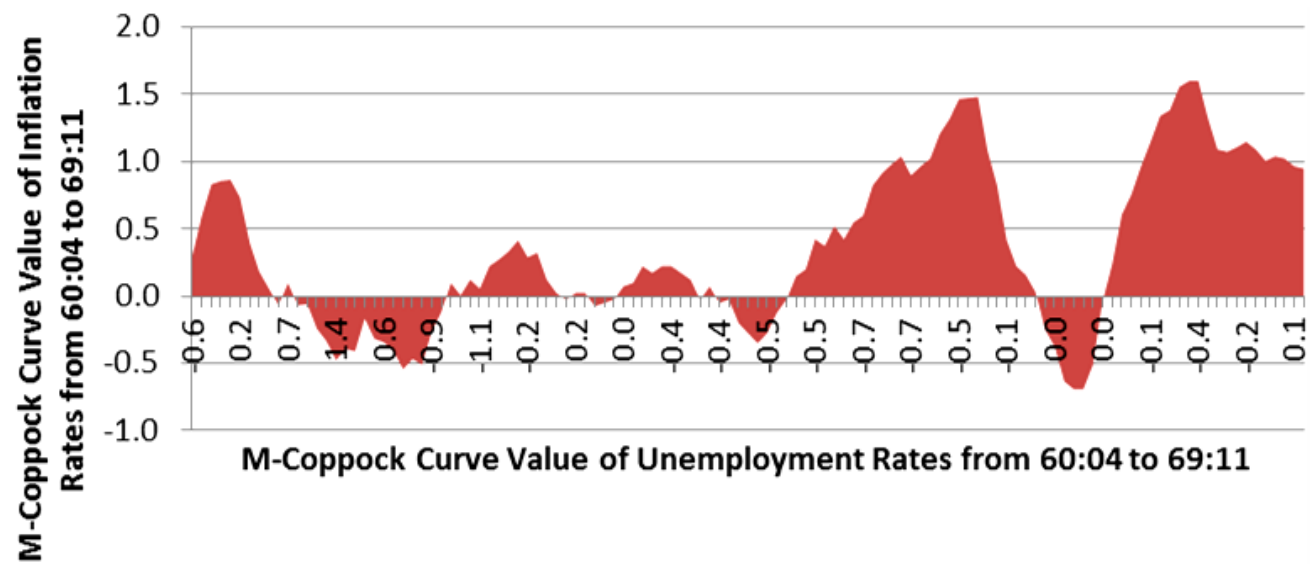

(b)

Figure 5. (a) Phillips curve, monthly from 60:04 - 69:11; (b) Phillips curve of M-Coppock curves: 60:04 - 69:11. 


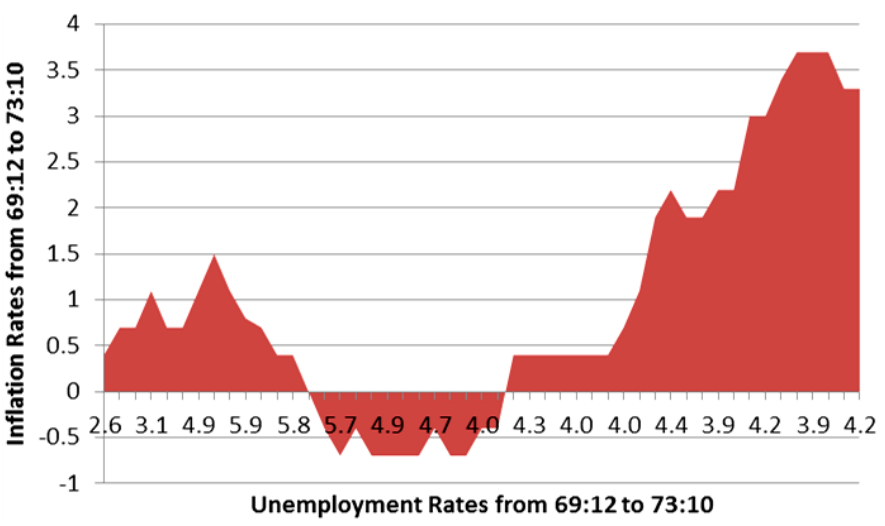

(a)

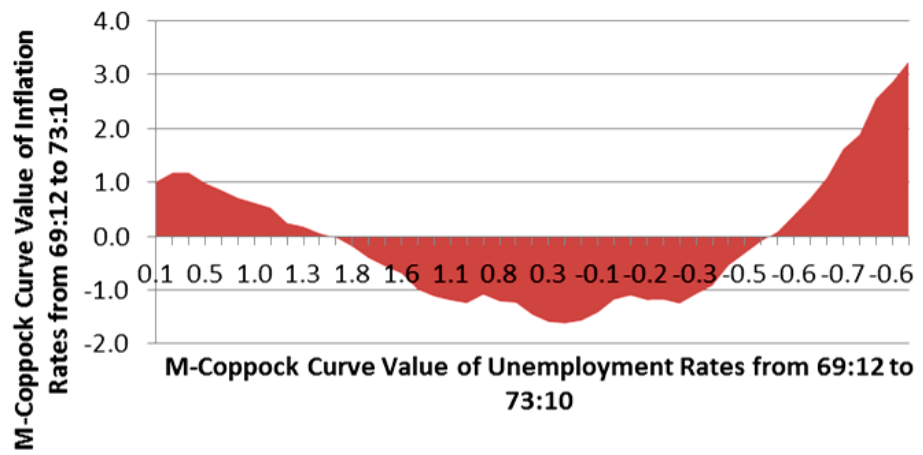

(b)

Figure 6. (a) Phillips curve, monthly from 69:12 - 73:10; (b) Phillips curve of M-Coppock curves: 69:12 - 73:10.

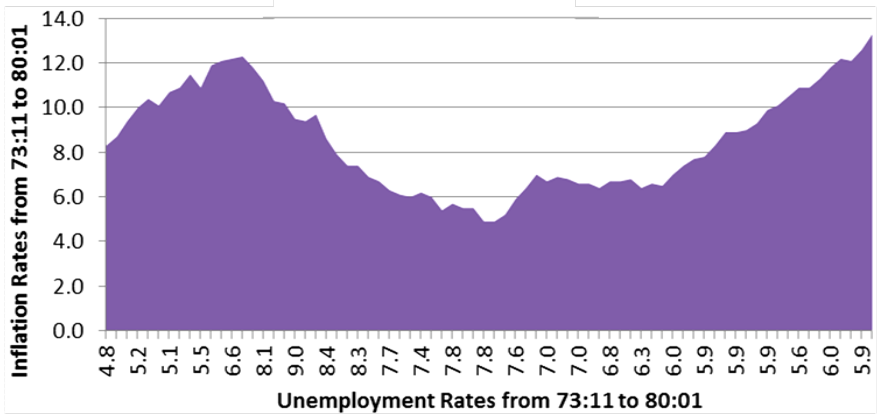

(a)

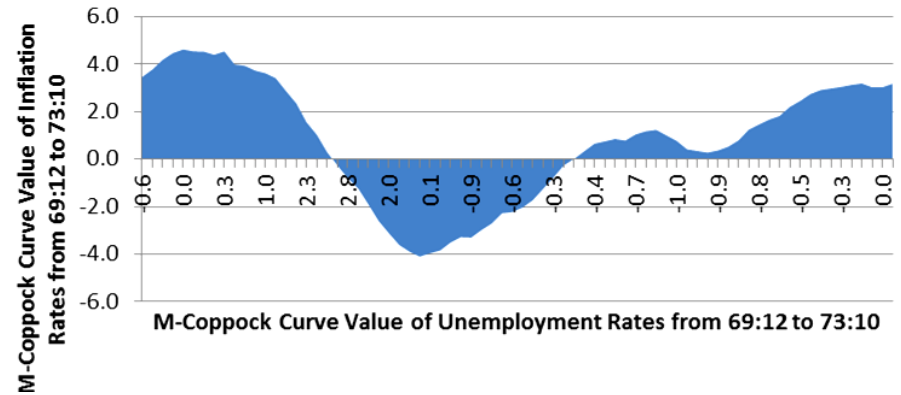

(b)

Figure 7. (a) Phillips curve, monthly from 73:11 - 80:01; (b) Phillips curve of M-Coppock curves: 73:11 - 80:01. 


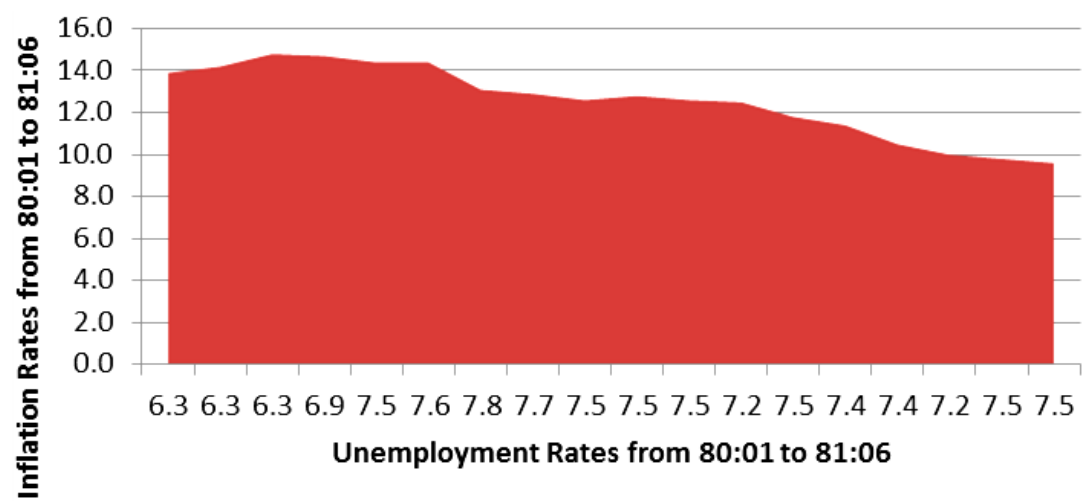

(a)

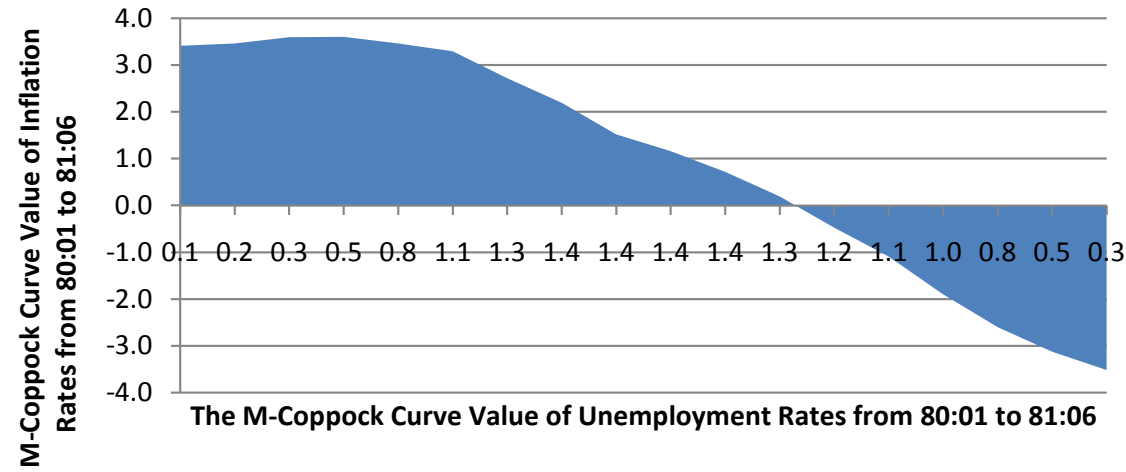

(b)

Figure 8. (a) Phillips curve, monthly from 80:01 - 81:06; (b) Phillips curve of M-Coppock curves: 80:01 - 81:06.

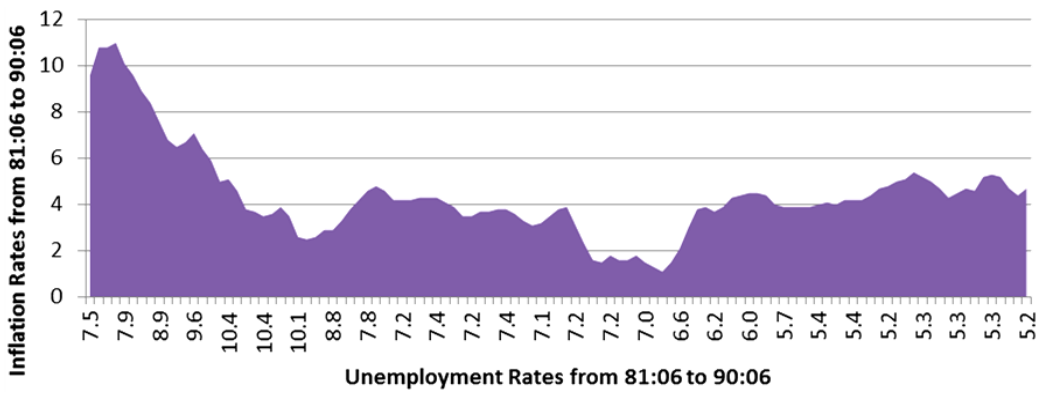

(a)

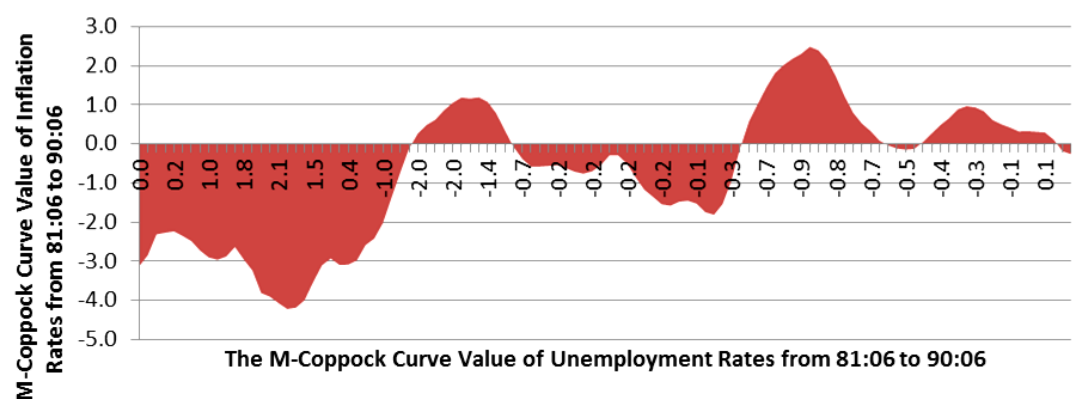

(b)

Figure 9. (a) Phillips curve, monthly from 81:06 - 90:06; (b) Phillips curve of M-Coppock curves: 81:06 - 90:06. 


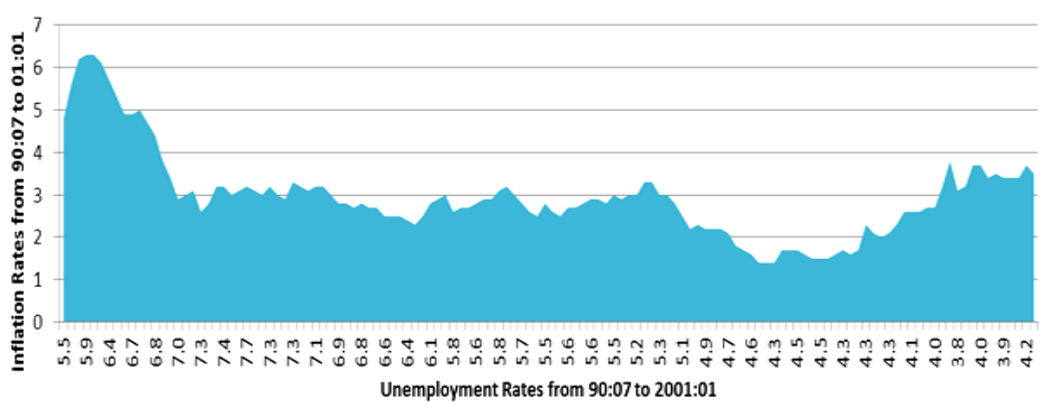

(a)

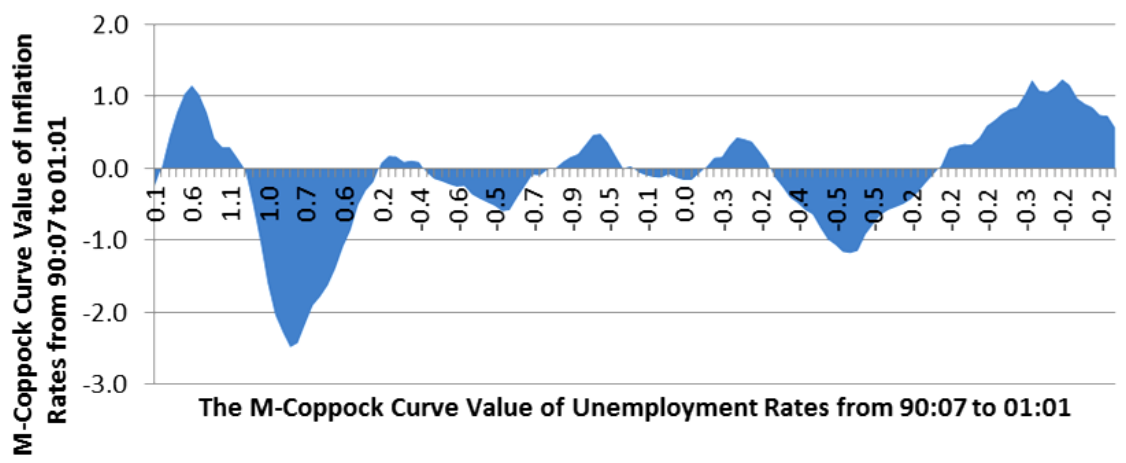

(b)

Figure 10. (a) Phillips curve, monthly from 90:07 - 2001:01; (b) Phillips curve of M-Coppock curves: 90:07 - 01:01.

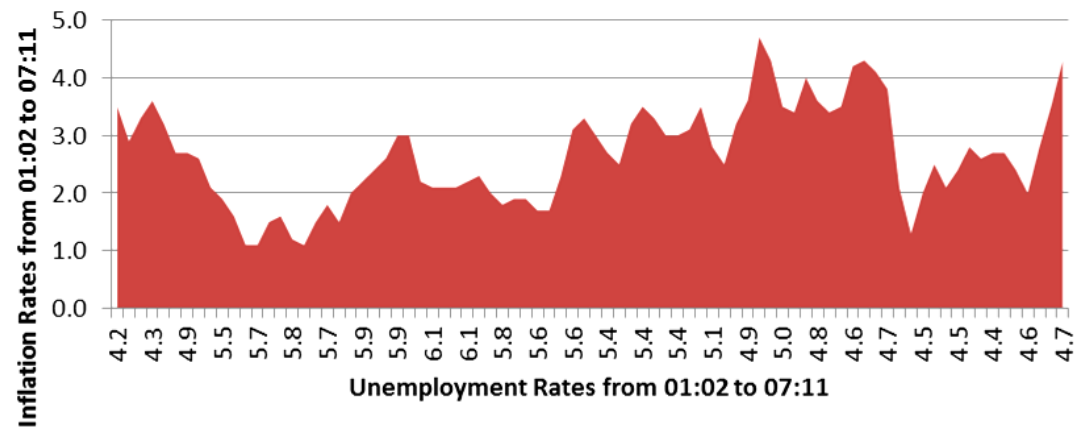

(a)

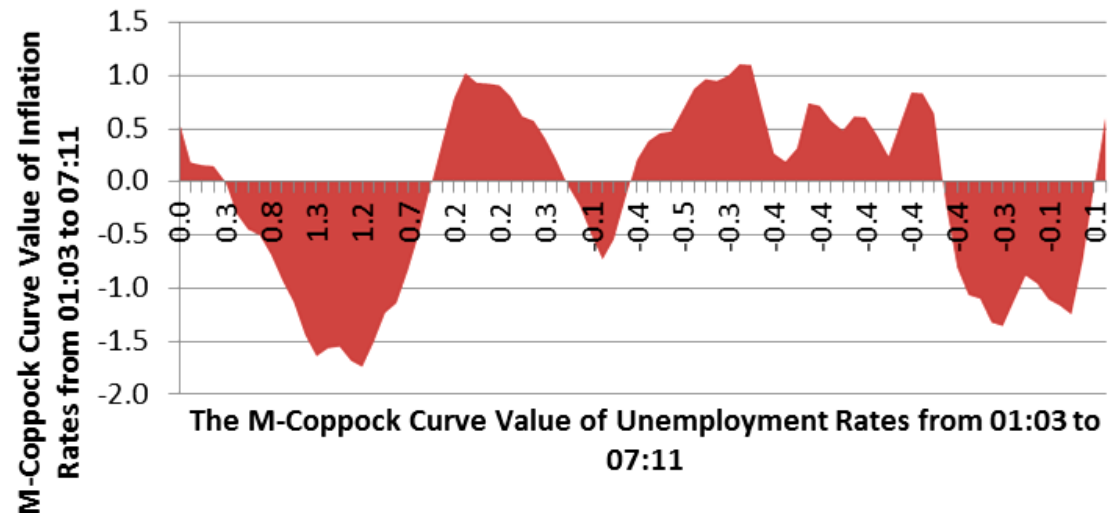

(b)

Figure 11. (a) Phillips curve, monthly from 01:02 - 07:11; (b) Phillips curve of MCoppock curves: 01:03 - 07:11. 


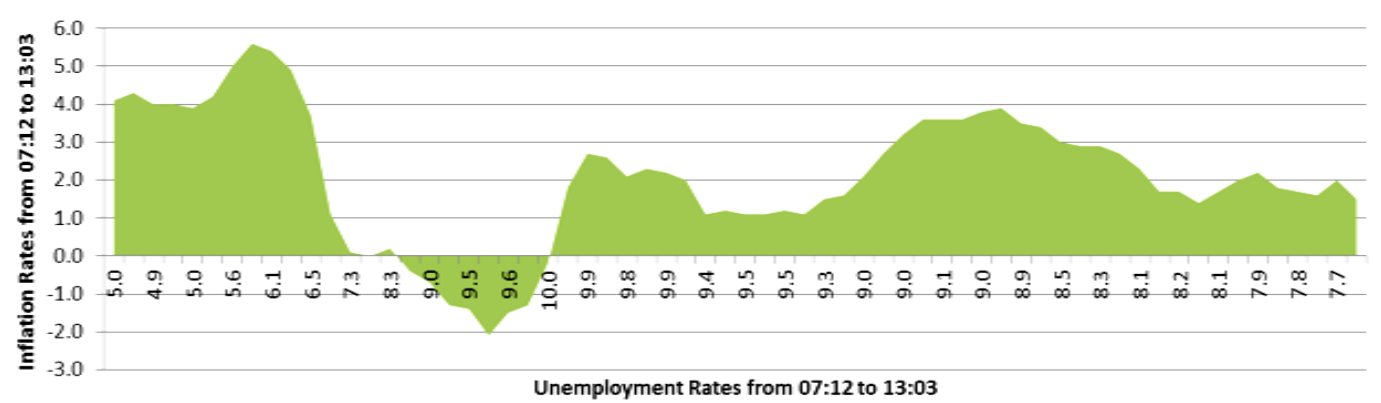

(a)

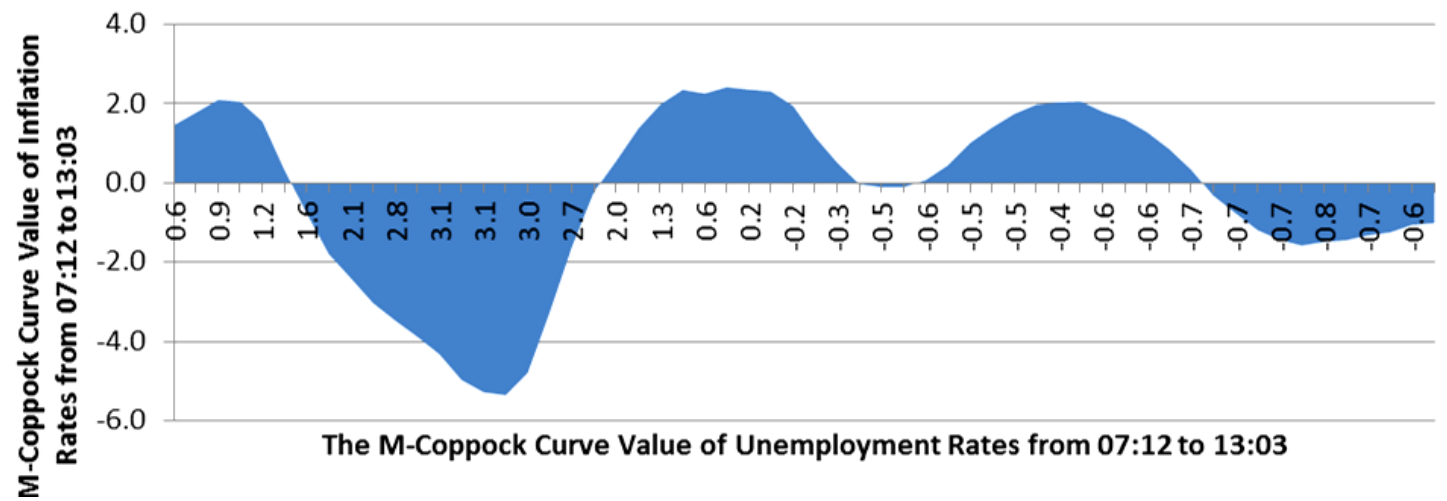

(b)

Figure 12. (a) Phillips curve, monthly from 07:12 - 13:03; (b) Phillips curve of M-Coppock curves: 07:12 - 13:03.

"When the demand for a commodity or service is high relatively to the supply of it we expect the price to rise, the rate of rise being greater the greater the excess demand. Conversely when the demand is low relatively to the supply we expect the price to fall, the rate of fall being greater the greater the deficiency of demand. It seems plausible that this principle should operate as one of the factors determining the rate of change of money wage rates, which are the price of labour services. When the demand for labour is high and there are very few unemployed we should expect employers to bid wage rates up quite rapidly, each firm and each industry being continually tempted to offer a little above the prevailing rates to attract the most suitable labour from other firms and industries."

In the well-known Friedman-Phelps models [3] [4], Phillips' excess demand is neither a sufficient condition nor a necessary condition for price inflation. Indeed, they show that any average rate of inflation can arise in their models with any level of unemployment (see Locus [5], p. 283 for a detailed discussion). But our finding is that Phillips' excess demand condition does matter for the price inflation near the end of each expansion (with only one exception in the 80's).

Phillips' original hypothesis has a second part that is about the impact of "excess supply" on the wage inflation:

"On the other hand it appears that workers are reluctant to offer their services at less than the prevailing rates when the demand for labour is low and unemployment is high so that wage rates fall only very slowly. The relation between unemployment and the rate of change of wage rates is therefore likely to be highly non-linear.”

Excess supply is supposed to be mostly tied to recessions under which unemployment rates arise to an abnormal high level. Here we found no evidence to support this part of his hypothesis about the slow decline in price inflation. In fact, we find the opposite holds true. A recession can bring down price inflation fast and substantially. Beyond these observations, we also offer a new idea why business cycles can be generated endogenously, based on a simple AD-AS analysis.

\section{Data and Methodology}

Our empirical work uses monthly data of the US economy from 1948:01 to 2013:03. The unemployment rate 
data is from the Bureau of Labor Statistics (BLS). The inflation data is the CPI data with 12 month percentage change for all items and all urban consumers with base period 1980-1984 $=100$. We first use a scatter-plot graph, as originally used by A.W. Phillips [2], to generate a graph between monthly inflation rates and unemployment rates. The graph is provided in Figure 1, which is again "chaotic", as shown similarly in Figure 1 in Ma [1] with the annual data. We will do three different things from Phillips [2] in this paper. First, we draw the relationship between the two rates along a business cycle from the beginning month of a recession to the beginning month of the imminent recession. A recession here is identified by the NBER dating committee. Second, we put the unemployment rates as they actually evolve along a business cycle in time in the horizontal axis while the corresponding inflation rates are put on the vertical axis. By doing this, one knows how the inflation evolves along time in a business cycle. Notice that the unemployment rate for the US economy for a business cycle has two trend lines. Unemployment rates climb higher in trend during a recession. The uptrend will turn to a downward trend in the subsequent expansion period. Some "humps or potholes" do exist along the two trends, but they are typically very small and brief. This means that the unemployment rate in each of our drawings in the horizontal axis increases at the beginning and then decreases, an upside down V-shape curve along time with a longer right leg since an expansion typically lasts longer than a recession. Third, we also draw the M-Coppock curve of the inflation rate against the M-Coppock curve of the unemployment rate along a business cycle. The M-Coppock curve is taken from Ma and Tang [6] and it is a modified version of the original Coppock curve used in the equity market. This Coppock curve approach enables us to see in a more smooth version when inflation is about to make a turn in its trend. These turning points can provide useful information for monetary policy of the Federal Reserve. We now introduce how to define this M-Coppock curve of a time series.

\section{M-Coppock Curve}

Edwin S.C. Coppock was an economist, who invented the Coppock curve, published by the Barron's Magazine on October 15th 1962, to identify the turning points of an index like the monthly S\&P500 index, using the 10-period weighted moving average (MA) of the sum of the 14-month rate of change (14-ROC) and the 11-month rate of change (11-ROC):

$$
\text { Coppock }=10 \text {-period weighted moving average }(\mathrm{MA}) \text { of the sum of }(14-\mathrm{ROC}+11-\mathrm{ROC}) \text {. }
$$

When we apply this indicator to the unemployment UR(k) time series, we modify the indicator as follows, as in Ma and Tang [6]:

$$
\operatorname{M-Coppock}(\mathrm{k})=12 \text {-period simple MA of the sum of }\left(\Delta_{1} \mathrm{UR}(\mathrm{k})+\Delta_{3} \mathrm{UR}(\mathrm{k})+\Delta_{6} \mathrm{UR}(\mathrm{k})\right) \text {, }
$$

where $\Delta_{\theta} \mathrm{UR}(\mathrm{k})=\mathrm{UR}(\mathrm{k})-\mathrm{UR}(\mathrm{k}-\theta)$, the $\theta$-period difference for $\theta=1,3$, 6. We select the first difference, one quarter difference and two quarter difference. Similarly, we can apply the M-Coppock curve to the inflation rate time series. Notice that the M-Coppock curve just uses the local information up to 18 periods. Such a curve is very different from an econometric method where an estimate typically uses the information of a whole sample.

Ma and Tang [6] use the M-Coppock curve of the unemployment rates to call recessions in real time. Here we draw the M-Coppock curve of the inflation rates (in the vertical axis) against the M-Coppock curve of the unemployment rates (in the horizontal axis) across different business cycles. We call these curves the Phillips curves of the M-Coppock curves.

\section{Empirical Findings}

Figure 1 is the plotting graph of the monthly unemployment and inflation rates. The graph is indeed "chaotic" and has no clear law that governs it. Such a pattern is the main reason why there is no clear relationship between the average rates of inflation and unemployment for the US economy. But some clear patterns appear if we draw the relationship between the rates along a business cycle. These drawings are provided from Figures 2 to 12, each of which consists of two graphs, one with the original two rates (Figures 2(a) to 12(a)) and the other with the two M-Coppock curves (Figures 2(b) to 12(b)).

We need to point out that the business cycle from 80:01 to 81:06 is a special instance because its expansion has been cut short due to an aggressive monetary policy of the Fed, which provides a monetary shock big enough to induce a subsequent recession starting in May 1981 [7]. That is the reason why we cannot observe the 
type of increase in inflation by the end of June 1981 because the expansion itself does not finish its "natural course". We now make two important observations that apply to all other business cycles. First, we observe that a recession can bring down inflation rates substantially. But the magnitude in the decline of inflation by a recession is different across different business cycles. Second, an expansion with a substantial duration eventually leads to an increase in inflation rates. Once again, the increase in inflation is also different across different business cycles. This means that what has been learnt about one business cycle about inflation cannot be simply extrapolated to others. That is, a model based on the relationship between the average rates of inflation and unemployment data in the past will likely fail in forecasting correctly a future relationship between the two rates.

When the economy has a recession, the M-Coppock curve of inflation rates either trends downward (some with short lags) or stay in the negative zone. That is, a recession provides an enormous pressure for the price level to move downward. Price rigidity has hardly been observed here. When the economy is in the middle stage of an expansion, no conclusive relationship between inflation and unemployment can be made. But, when an expansion approaches its end, the M-Coppock curve of inflation either starts to trend upward or stays in the positive zone. That means that an expansion with a substantial duration also provides an enormous pressure for inflation to climb higher. These M-Coppock curves during a recession or an expansion are different from one another. This implies that the relationship between inflation and unemployment should just be limited to individual business cycles. That is, the decline in inflation due to a recession and the increase in inflation due to an expansion are two phenomena with local properties. This helps demonstrate why the average approach can be wrong.

One implication of these charts is that business cycles may not be purely due to external shocks, in contrast to a claim in the real business cycle theory. Higher inflation caused by an expansion reduces real balance of money supply. A reduction in money supply by the Fed would reduce the real balance of money supply further. No wonder why there were so many recessions in the past that were caused by monetary policy shocks [7]. Such shocks should not be simply classified as external shocks because they were implemented to accommodate the inflation caused by the related expansion, which should be considered as an endogenous process.

\section{Current Cycle}

Let us examine the current cycle and see what advice we can give to the Fed. The chart for the current business cycle is given in Figures 12(a) and (b). From Figure 12(a), we can see that the 2007 recession has brought down inflation from the peak $5 \%$ to the negative $2 \%$ trough in a very short period of time. Along with the recession, the M-Coppock curve of inflation also forms a downtrend. A short lag exists right after the recession. At present, by looking at the Figure 12(a) alone, one cannot make any conclusion if inflation will go up or down in the near future. Nevertheless, because the M-Coppock curve is in the negative zone in Figure 12(b), we can conclude from here that there is a downward pressure in inflation now. This downward pressure will persist for some time because the M-Coppock curve in March 2013 has negative 1, too "far away" from zero. Notice that the M-Coppock curve has a weak upward trend, with values of $-1.6,-1.5,-1.5,-1.3,-1.3,-1.1,-1.0$ from 2012:09 to 2013:03. If the trend continues with the same pace, we will expect to have a positive value of the M-Coppock curve ten months from March 2013, which will be around January 2014. That will be about the time we should watch an upward trend in the inflation. Thus, inflation rate can have some momentum to go down now but the downward pressure will gradually lose its momentum. This should be a good piece of news for the Fed. From now to January 2014, the Fed has ten month window period to make a change in its policy. The value of the M-Coppock curve of the unemployment rate is now at negative 0.5 . To have a recession, this value needs to be positive 0.2 or above (see Ma and Tang [6]). This means that one should not worry about much at the moment if the economy can get into another recession due to a shift in monetary policy. A warning sign is that the M-Coppock curve of the unemployment rate ticks upward, with values of $-0.8,-0.8,-0.8,-0.7,-0.6,-0.6$, -0.5 from September 2012 to March 2013. Moreover, a recession can occur if monetary shocks are big enough, as observed in the 80's. This means that the Fed should exit the existing quantitative easing policy earlier but with a gradual and slower pace. If the Fed waits for too long, a dramatic shift may be needed to tame inflation later.

It should be aware that an extreme low rate can cause money-hoarding by corporations and banks because the opportunity cost of holding money is too low. According to Moody's, non-financial corporations alone are now holding about 1.5 trillion dollar worth of cash. A higher rate can reduce money-hoarding by corporations due to higher opportunity costs. Moreover, a higher rate also signals a healthier economy. A distorted low rate also 
distorts falsely the reality in the underlying economy. Therefore, a shift in monetary policy for a moderate rise in rates may not necessarily reduce money supply, in contrast to what has been commonly believed.

\section{Business Cycles}

We now use a simple model of AD-AS analysis to explain why an expansion with a substantial duration leads to a higher inflation and a recession. Why does a recession end? We will also provide an answer to the question why expansions on average last longer than recessions. No external shocks are needed in our analysis below because we aim at a theory that business cycles can be generated endogenously.

Figure 13(a) provides a model how an economy expands in a normal pace. When an economy expands in a normal pace with a net number of new (indivisible) labors hired, AD and AS both increase due to increase in the size of labor. A consequence of that is a higher output. The price level can be higher or lower, depending on the magnitude in the shifts of AD and AS. This explains well why it is typically inconclusive in the middle of an expansion about the relationship between inflation and unemployment, as observed in Figures 2(a)-12(a). Notice that wars can increase AD with a large scale. So a higher inflation is expected during a war time. Korean and Vietnam wars are two good examples.

Things are quite different when an expansion lasts for a substantial duration. As an expansion proceeds, the aggregate demand continues to increase because of the new net hiring. But, with a tight labor market, there are three sources that may in fact reduce aggregate supply with the new net hiring. First, a tight labor market may cause wages higher for the new hiring and the existing employees. Second, a tight labor market can cause higher turnover rates. Third, a tight labor market may increase the chance of shirking in the workplace (see, e.g., Shapiro and Stiglitz [8]). These three forces together can cause a reduction in AS, as shown in Figure 13(b). A consequence of that is a higher inflation rate and a lower output. But notice that the output that can be produced is in fact higher, not lower, due to the new net hiring. It is just that the output at equilibrium is lower. This is the major difference between Figures 13(a) and (b). In Figure 13(a), output at equilibrium equals the output of production. That is, what can be sold equals what may be produced in Figure 13(a). However, in Figure 13(b), the output that can be produced by the existing and the new hired workers is higher than the output at equilibrium. This means that inventory in Figure 13(b) will increase. Firms need to lay off workers eventually to lower the production to equilibrium level. But a layoff, an economy wide, will substantially reduce aggregate demand and aggregate supply, as shown in Figure 14(a). The imbalance in the equilibrium output and the output in production triggers layoffs, which in turns lead to a recession.

When a recession begins, the process can persist as shown in Figure 14(a) due to decreases in both AD and AS. But, near the end of a recession, layoffs may continue, resulting in a lower demand (Figure 14(b)). Because the labor market now has a great number of unemployed workers, the three adversary factors associated with a tight labor market above become beneficial to the firms. Aggregate supply curve can in fact shift to the right even if layoffs continue. Now notice that output at equilibrium has been produced by a less number of workers. This is possible because firms have retained higher productive workers on average. Labor-hoarding during a recession is also a factor now to produce a higher output without new hiring, a process that may last for a certain period, resulting in a "jobless recovery”. But this “jobless recovery” process cannot persist forever. Sooner or later firms must hire new workers as the recovery moves forward. A new expansion begins, as shown in Figure 13(a). The economy is on a track of a new cycle.

Using the models in Figures 13(a) and (b) and Figures 14(a) and (b), we can also explain why recessions typically last shorter than expansions. During an expansion, a new hiring must be done in a gradual process. We hardly observe any incumbent firm that hires a great number of workers once for all. Job search and match friction often prevents firms from hiring in a massive number of workers each time. Even a startup firm may not be able to hire all workers at once. This means that the shifts in Figure 13(a) are a slow-moving process. In contrast, during a recession, things are quite different. Layoffs in a firm during a recession are done in just a few rounds with each round a potentially massive number. The shifts in AD-AS in Figure 14(a) can be dramatic and persistin a short period of time. This explains well why expansions last typically longer than recessions in the absence of large external shocks. Of course, external shocks big enough may derail such a process. Our conclusion will not hold in that circumstance.

Why does a firm lay off workers massively? We first need to understand that a market for a product can be seen as an open accessible place (e.g., the market for smartphones, and consider the market as an ocean). Then firms (e.g., Apple, Google and Samsung) compete for consumers (now consider a consumer as a fish in the 


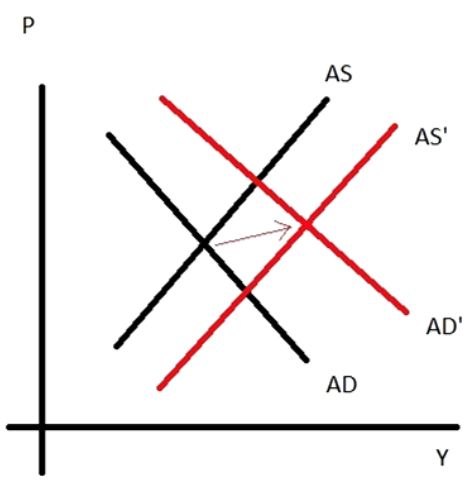

(a)

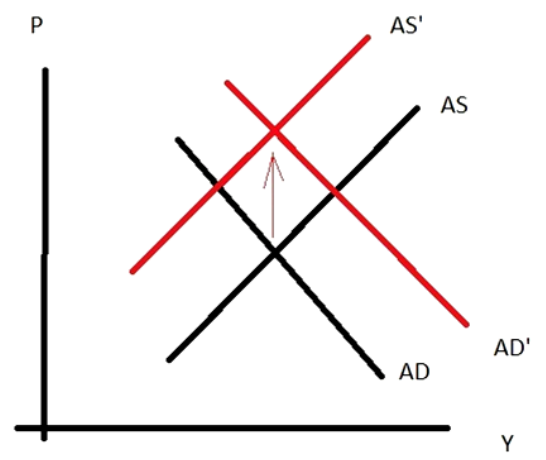

(b)

Figure 13. (a) Economy is in a normal expansion pace; (b) An expansion leads to a recession.

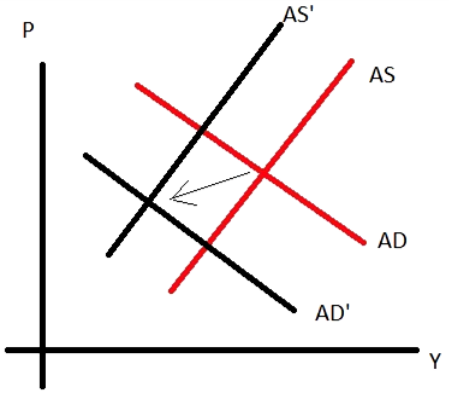

(a)

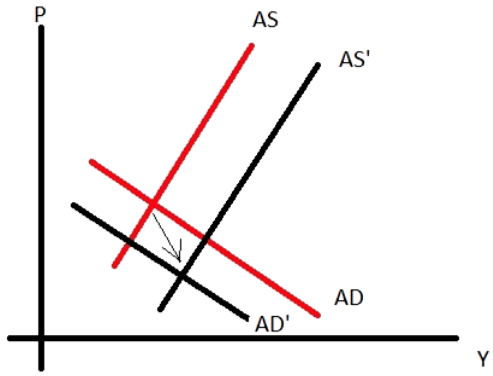

(b)

Figure 14. (a) A recession reduces AD and AS, resulting in lower inflation and output; (b) Layoff continues, resulting lower AD. But AS increases, resulting lower price level and higher output.

ocean). We now consider the number of employees in a firm as its effort to compete for consumers. Then, in the hiring practice, firms hire additional workers as long as the average revenue of an additional worker is at least as high as the average cost of hiring. In an open accessible market, hiring practice only involves the average revenue and cost. This can result in a "tragedy of the commons" [9], a consequence of an economic inefficiency in the competition for an open accessible resource.

There are two types of externalities that are relevant here. The demand curve of a product may increase by each net new hiring. That is, a net new hiring by firm A may create a positive externality for products of firm B. Thus, a hire in firm A also provides incentive for firm B to add new workers. This means that a hiring practice in a firm cannot be done once for all because the increase in the demand of a product for a firm itself is a gradual process.

On the other hand, such a new hiring may also create a negative externality in the labor market because the new hiring by firm A may cause firm B to pay more to hire an additional worker or to the existing workers. During the recovery, the positive externality in the product market should dominate the negative externality in the labor market, resulting in a gradual hiring boom. But the fortune can turn when the labor market becomes tight, just like the time period near the end of an expansion with a substantial duration. When the negative externality in the labor market dominates the positive externality in the product market, a new hiring by firm A can provide incentive for firm B to lay off workers rather than hire new workers.

How does a firm lay off workers? A firm will lay off a worker as long as his marginal revenue is less than his wage paid. Massive layoffs become possible because the two marginal curves cross each other at a level that is much lower than that at which the two average curves cross each other. This provides a good reason why firms often lay off workers with a massive number. Notice that it is at this level of labor where the average revenue of labor now becomes higher than the average cost of a new hiring. Thus, when the market condition for a product improves, a firm has a good reason to add new workers. 


\section{Conclusions}

The relationship between inflation and unemployment for the US economy is important for the monetary and fiscal policies. We have seen that a conclusion that is obtained from the data in the past casts very little light quantitatively on the relationship that has been undergoing in an economy. The relationship between the two rates has a local property in the sense that it is specific to each business cycle. But there is a lesson that is common among all the recessions we have examined: a recession drags down inflation while an expansion of a substantial duration eventually gives rise to a higher inflation. However, the magnitudes in the decline or increase in inflation are all different across different business cycles. The M-Coppock curves of the two rates use the local information of the two rates (up to 18 months) and provide important information about how inflation may evolve in a business cycle. This tool should remain to be useful for correctly conducting monetary or fiscal policy in the future.

We also use a simple AD-AS analysis to illustrate why a business cycle can be generated endogenously. We explain why expansions can last longer than recessions. Some key differences in job hiring and layoff practices are also discussed. The limitation of this paper is that our analysis is just for the US economy.

\section{References}

[1] Ma, J. (2012) Mystery of Modern Phillips Curve. Modern Economy, 3, 907-914. http://dx.doi.org/10.4236/me.2012.38113

[2] Phillips, A.W. (1958) The Relation between Unemployment and the Rate of Change of Money Wage Rates in the United Kingdom, 1861-1957. Economica, 25, 283-299.

[3] Friedman, M. (1968) The Role of Monetary Policy. American Economic Review, 58, 1-17.

[4] Phelps, E.S. (1967) Phillips Curves, Expectations of Inflation and Optimal Unemployment over Time. Economica, 34, 254-281. http://dx.doi.org/10.2307/2552025

[5] Lucas, R.E. (1981) Studies in Business Cycle Theory. The M.I.T. Press, Cambridge.

[6] Ma, J. and Tang, M. (2012) Forecast Post-World War II Recessions in Real Time. Rutgers University, Camden.

[7] Temin, P. (1998) The Causes of American Business Cycles: An Essay in Economic Historiography. NBER Working Paper Series, wp6692.

[8] Shapiro, C. and Stiglitz, J. (1984) Equilibrium Unemployment as a Worker Discipline Device. American Economic Review, 74, 433-444.

[9] Hardin, G. (1968) The Tragedy of the Commons. Science, 162, 1243-1248. http://dx.doi.org/10.1126/science.162.3859.1243 